\title{
Synthesis and Photocatalytic Activity of Monolithic $\mathrm{Fe}_{2} \mathrm{O}_{3} / \mathrm{TiO}_{2}$
}

\author{
Wei Chang ${ }^{\mathrm{a}, *}$, Maojin Zhang ${ }^{\mathrm{a}}$, Xiaosai Ren ${ }^{\mathrm{a}}$ and Andrew Miller \\ ${ }^{a}$ School of Environmental and Chemical Engineering, Xi'an Polytechnic University, Xi'an 710048, China \\ ${ }^{b}$ Emporia State University, Emporia, KS, 66801-5087, USA \\ Received 14 March 2017, revised 11 September 2017, accepted 13 September 2017
}

\begin{abstract}
The monolithic $\mathrm{Fe}_{2} \mathrm{O}_{3} / \mathrm{TiO}_{2}$ composites were synthesized via a one-pot sol-gel process with titanium tetrachloride as a Ti source and ferric chloride as a Fe source. The monolithic $\mathrm{Fe}_{2} \mathrm{O}_{3} / \mathrm{TiO}_{2}$ composites were characterized by scanning electron microscopy, powder $\mathrm{XRD}, \mathrm{N}_{2}$ /adsorption-desorption, fluorescence and UV-vis diffuse reflectance spectroscopy. The photocatalytic activity of the $\mathrm{Fe}_{2} \mathrm{O}_{3} / \mathrm{TiO}_{2}$ composites were evaluated by degradation of bisphenol A. The results indicated that, with the doping of Fe, the surface area of the monolithic $\mathrm{Fe}_{2} \mathrm{O}_{3} / \mathrm{TiO}_{2}$ increased, the forbidden band width decreased and the electron-hole recombination rate decreased. The monolithic $\mathrm{Fe}_{2} \mathrm{O}_{3} / \mathrm{TiO}_{2}$ composite with $\mathrm{Fe} / \mathrm{Ti}$ molar ratio of 0.03 had the best photocatalytic activity for degradation of bisphenol A.
\end{abstract}

KEYWORDS

Sol-gel process, $\mathrm{Fe}_{2} \mathrm{O}_{3} / \mathrm{TiO}_{2}$, photocatalysis.

\section{Introduction}

In recent years, with the development of industry, the pollution of water has become a serious problem to the normal ecological environment. Typically, pharmaceuticals and personal care products (PPCPs), as a series of new reported contaminants, have had a persistent and unrecoverable impact on the environment even though their concentration in the environment is very low. Bisphenol A (BPA), one of the PPCPs, may potentially create adverse health effects. It is reported that BPA has been frequently detected in rivers and drinking water and is difficult to remove effectively with traditional methods. ${ }^{1,2}$

Nano $\mathrm{TiO}_{2}$ is an efficient photocatalyst and has attracted much attention with the increasing environmental problems because of its stable chemical properties, non-toxic character and no secondary pollution. ${ }^{3}$ However, $\mathrm{TiO}_{2}$ has a wide band gap energy of about $3.2 \mathrm{eV}$ for the anatase structure and $3.0 \mathrm{eV}$ for rutile structures and thus only a small fraction of the solar spectrum $(5 \%)$ is absorbed. ${ }^{4}$ On the other hand, the recombination probability of photo-generated electrons and holes is higher, leading to a lower photocatalytic efficiency. To extend the photo-response region of $\mathrm{TiO}_{2}$ from the UV to visible region and to overcome this electron-hole recombination, some different methods have been applied, such as doping with $\mathrm{Nd}, \mathrm{Cu}, \mathrm{Fe}$ and $\mathrm{Ag}^{5-9}$ noble metal deposition, ${ }^{10-13}$ sensitization, ${ }^{14}$ composite formation, ${ }^{15}$ and the coupling of $\mathrm{TiO}_{2}$ with other metal oxides. ${ }^{16-20}$ Among them, ferric oxide is known to have a narrow band gap of $2.2 \mathrm{eV}$ and can be used as a visible light photocatalyst in industrial applications due to its low cost, non-toxicity and high chemical stability. ${ }^{21} \mathrm{Fe}_{2} \mathrm{O}_{3}$ modified $\mathrm{TiO}_{2}$ was investigated extensively for its potential application in degradation of organic pollutants. It has been shown that combination of $\mathrm{Fe}_{2} \mathrm{O}_{3}$ and different $\mathrm{TiO}_{2}$ nanostructure can not only extend the spectra absorption range, but can also develop a defect structure for the separation of photo-generated electrons and holes. In addition, most of the reported materials have a nanostructure, which is difficult to

* To whom correspondence should be addressed. E-mail: changwei72@163.com separate after the photocatalytic reaction process. The film type photocatalysts increased the recovery efficiency but reduced the specific surface area, resulting in low photocatalytic activity. ${ }^{22}$

Therefore, how to remove all kinds of contaminants effectively and in an environmentally-friendly manner is becoming a focused area of current research. In this study, the monolithic $\mathrm{Fe}_{2} \mathrm{O}_{3} / \mathrm{TiO}_{2}$ was synthesized by the sol-gel process. The monolithic material has a macro and mesopore structure. Meanwhile, the Fe doping extends the range of the light response of the material. The photocatalytic activity of the monolithic $\mathrm{Fe}_{2} \mathrm{O}_{3} / \mathrm{TiO}_{2}$ was evaluated by degradation of BPA in aqueous solution using a $500 \mathrm{~W}$ xenon lamp.

\section{Experimental}

\subsection{Materials}

Titanium tetrachloride $\left(\mathrm{TiCl}_{4}\right)$ was obtained from Tianjin Fuchen Chemical Reagents Co., Ltd. Poloxamer (F127) was purchased from BASF chemical company in Germany. Absolute ethyl alcohol $\left(\mathrm{CH}_{3} \mathrm{CH}_{2} \mathrm{OH}\right)$, furfuryl alcohol $\left(\mathrm{FA}, \mathrm{C}_{5} \mathrm{H}_{6} \mathrm{O}_{2}\right)$, ferric trichloride $\left(\mathrm{FeCl}_{3} \cdot 6 \mathrm{H}_{2} \mathrm{O}\right)$, and bisphenol $\mathrm{A}(\mathrm{BPA})$ were obtained from Sinopharm Chemical Reagents Co., Ltd. Millipore water $\left(\mathrm{R}>18 \mathrm{M} \Omega^{*} \mathrm{~cm}^{-1}\right)$ was used in all experiments. All reagents were used as received.

\subsection{Characterization}

The morphology of all the samples was observed by scanning electron microscopy (SEM) performed on a QUATA FEG 450 field emission instrument operated at an accelerating voltage of $5.0 \mathrm{kV}$. The crystal structure of the samples were analyzed by XRD (Rigaku, Dmax-Rapid II) with $\mathrm{Cu}-\mathrm{K} \alpha$ radiation $(\lambda=0.15418 \mathrm{~nm}, 40 \mathrm{kV}, 40 \mathrm{~mA})$. The scanning range was from $20^{\circ}$ to $80^{\circ}$. The surface areas of samples were determined from nitrogen adsorption-desorption isotherms at liquid nitrogen temperature using a 2390 Micromertics instrument. The photoluminescence (PL) spectra of the samples were recorded by 
RF-5301PC (Japan) spectrofluorometer at the excitation wavelength of $350 \mathrm{~nm}$. The scanning speed was $1200 \mathrm{~nm} \mathrm{~min}^{-1}$, the PMT voltage $700 \mathrm{~V}$ and the width of the excitation slit and emission slit was $10.0 \mathrm{~nm}$. UV-vis diffuse reflectance spectra were recorded at room temperature on a Lambda 950 instrument.

\subsection{Preparation of Monolithic $\mathrm{Fe}_{2} \mathrm{O}_{3} / \mathrm{TiO}_{2}$ and $\mathrm{TiO}_{2}$}

Firstly, $2.6 \mathrm{~mL} \mathrm{TiCl}_{4}$ was slowly added into $56 \mathrm{~mL}$ ethyl alcohol in ice water bath, and then, $1.8 \mathrm{~g}$ F127 was dissolved completely in the above solution. Secondly, $225 \mu \mathrm{L} \mathrm{FeCl}_{3}$ solution, and $2.27 \mathrm{~mL}$ FA were added to the mixture, stirring for $15 \mathrm{~min}$. The molar ratio of $\mathrm{Fe} / \mathrm{Ti}$ was $0.005,0.01,0.02,0.03$, respectively. The mixed solution was kept in an oven at $60^{\circ} \mathrm{C}$ for 5 days, and then at $130{ }^{\circ} \mathrm{C}$ for 3 days. Finally, the sample was calcined at $450{ }^{\circ} \mathrm{C}$ for $2 \mathrm{~h}$. The obtained samples with Fe/Ti molar ratio of $0.005,0.01$, $0.02,0.03$ were marked as FT0.5, FT1, FT2, FT3, respectively. The prepared sample without iron was marked as FT0. ${ }^{23}$

\subsection{Photocatalytic Activity Test}

Photocatalytic performance of the prepared samples were investigated by degrading BPA. The photocatalytic experiments were conducted in a photocatalytic reactor (BL-GHX-V). In the experiment, a $500 \mathrm{~W}$ xenon lamp (190-1100 nm) was employed as the light source. Prior to irradiation, $50 \mathrm{~mL}$ of BPA $\left(2 \times 10^{-5}\right.$ mol L-1 ) aqueous solution containing $30 \mathrm{mg}$ sample was magnetically stirred in the dark for $60 \mathrm{~min}$ to achieve adsorption/desorption equilibrium and a good dispersion. During the photoreaction, the samples were collected at regular intervals $(1 \mathrm{~h})$ and centrifuged to remove the sample. The supernatant solution before and after degradation was analyzed by a UV-visible spectrophotometer (UV-2450, Shimadzu) at $225 \mathrm{~nm}$. The remaining BPA concentration (\%) after various time intervals could be estimated with the following equation:

$$
\% \text { BPA concentration }=\mathrm{C} / \mathrm{C}_{0} \times 100 \%
$$

where $\mathrm{C}_{0}$ is initial concentration of BPA in solution, while $\mathrm{C}$ is the concentration at $t h$, respectively. The test process was repeated three times.
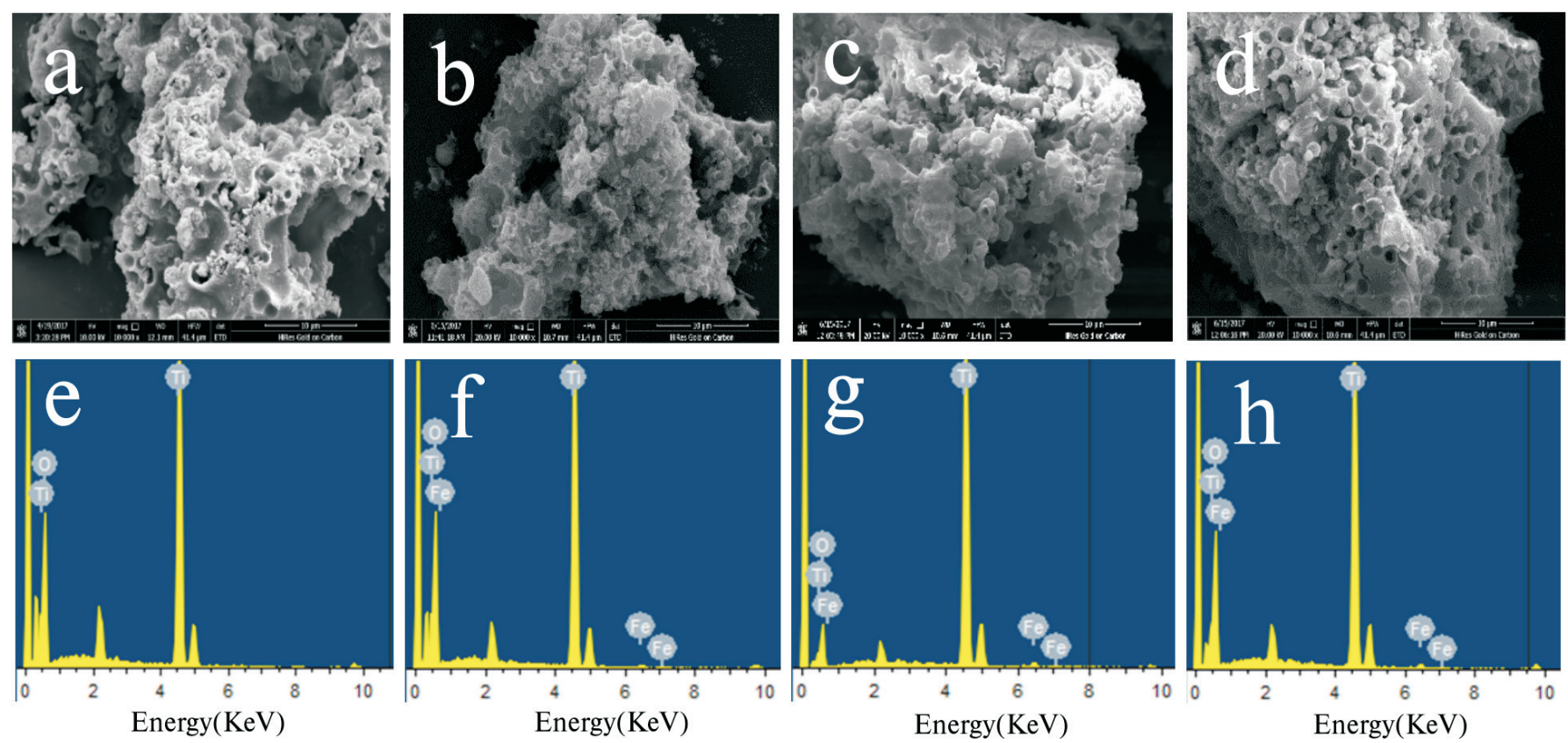

Figure 1 (a-d) SEM images of FT0, FT1, FT2, FT3; (e-h) EDS of FT0, FT1, FT2, FT3. 


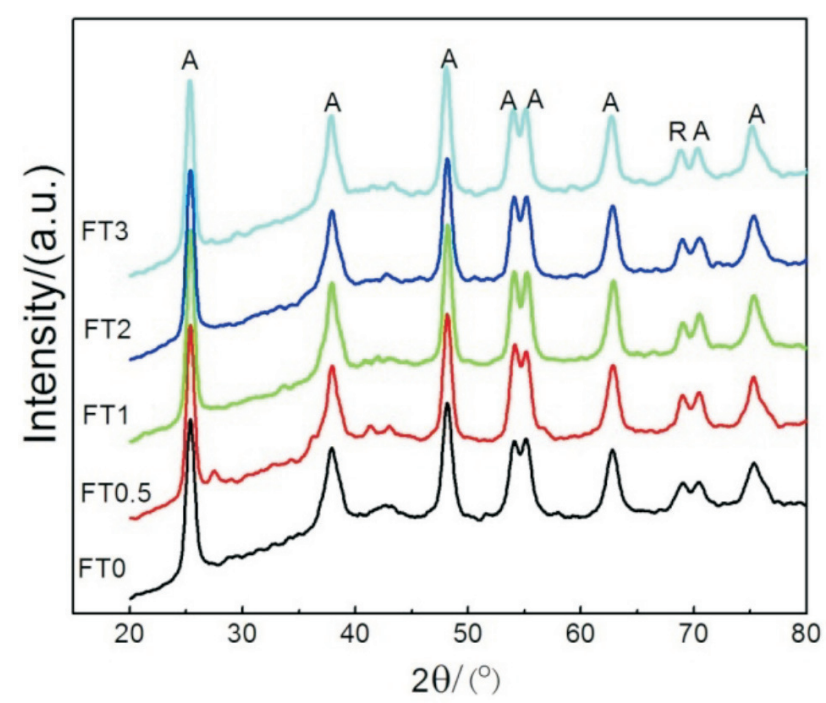

Figure 2 XRD patterns of prepared samples.

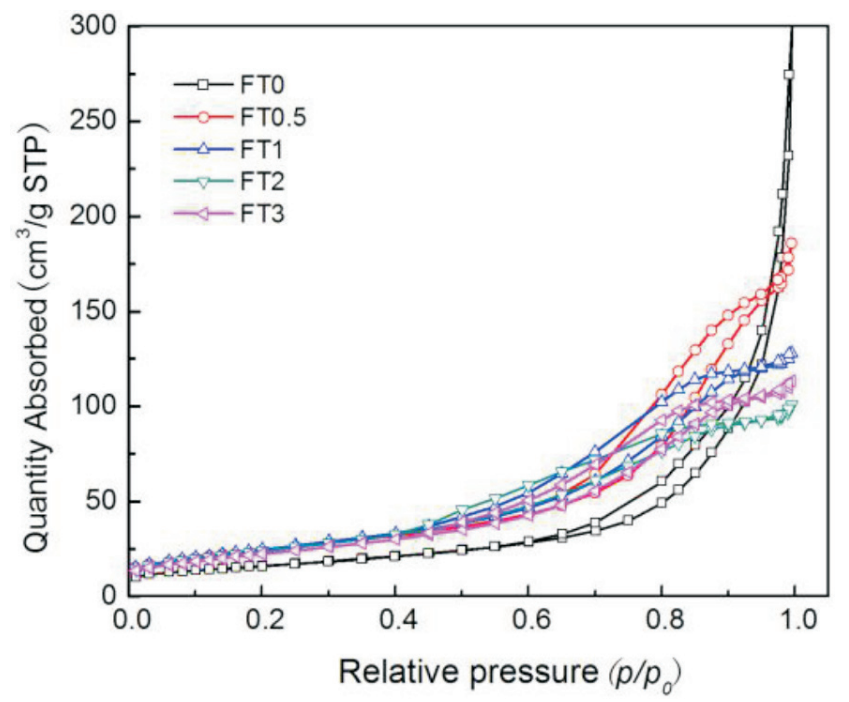

Figure 3 Nitrogen adsorption-desorption isotherms of prepared samples.

distribution calculated by the BJH model are shown in Table 1, which suggests that the specific surface area of the samples increased after doping iron. The average pore diameter of the prepared samples was between $5 \sim 25 \mathrm{~nm}$, showing that the samples have mesoporous structure. The results suggested that Fe doping would affect the porous structure of the monolithic $\mathrm{TiO}_{2}$.

\subsection{Photoluminescence Spectroscopy}

The photoluminescence spectra of all samples excited at $350 \mathrm{~nm}$ are shown in Fig. 4. The photoluminescence spectroscopy of semiconductor caused by the electronic-hole recombination, and the smaller the carrier recombination rate was, the

Table 1 Textural properties of the prepared samples.

\begin{tabular}{lccc}
\hline Samples & $\mathrm{BET} / \mathrm{m}^{2} \mathrm{~g}^{-1}$ & Pore volume $/ \mathrm{cm}^{3} \mathrm{~g}^{-1}$ & Pore size $/ \mathrm{nm}$ \\
\hline FT0 & 56.62 & 0.4698 & 23.5 \\
FT0.5 & 85.56 & 0.4218 & 9.5 \\
FT1 & 87.73 & 0.1974 & 6.3 \\
FT2 & 85.03 & 0.1546 & 5.2 \\
FT3 & 80.11 & 0.1745 & 6.1 \\
\hline
\end{tabular}

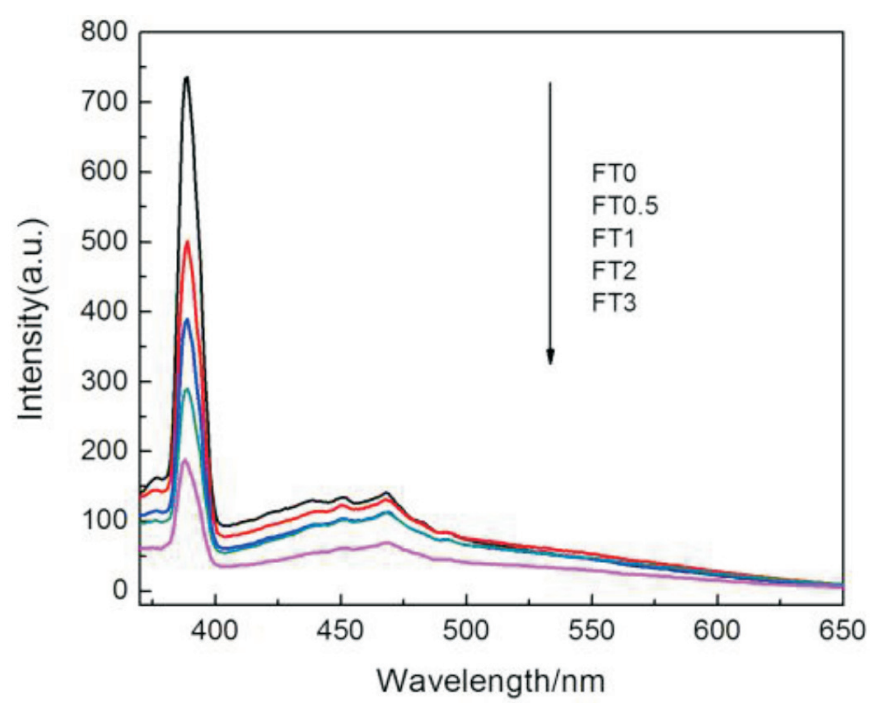

Figure 4 Fluorescence spectra of prepared samples.

lower photoluminescence intensity. ${ }^{26,27}$ As can be seen in Fig. 4, the intensity of PL decreased with the increasing Fe content, which implies the electron-hole recombination rate tends to be lower with the doping of $\mathrm{Fe}$ in the monoliths and hence have higher separation efficiency for electronic-hole pairs. When the recombination rate decreases, more photo-generated charge carriers can participate in the photochemical transformation, resulting in the enhancement of photocatalytic activity. ${ }^{28}$ It can be inferred that the Fe incorporated into the $\mathrm{TiO}_{2}$ can act as the electron-trapping agent to promote the electron-hole separation.

\subsection{UV-vis Diffuse Reflectance Spectra}

Figure 5 displays the DRS of monolithic $\mathrm{TiO}_{2}$ and $\mathrm{Fe}_{2} \mathrm{O}_{3} / \mathrm{TiO}_{2}$ samples. Compared with the absorption spectrum of monolithic $\mathrm{TiO}_{2}$, there is an obvious absorption extending to more than $400 \mathrm{~nm}$ for the $\mathrm{Fe}_{2} \mathrm{O}_{3} / \mathrm{TiO}_{2}$ sample, which is ascribed to the contribution from $\mathrm{Fe}_{2} \mathrm{O}_{3}$. According to the extension method, ${ }^{29}$ the light absorption threshold and forbidden band gap of samples were evaluated and the results are shown in Table 2 . The band gap of monolithic $\mathrm{TiO}_{2}$ was calculated to be $3.02 \mathrm{eV}$. The forbidden band gap decreased after doping with $\mathrm{Fe}$, and when $\mathrm{Fe}_{2} \mathrm{O}_{3} / \mathrm{TiO}_{2}$ composite with $\mathrm{Fe} / \mathrm{Ti}$ molar ratio of 0.03 , the forbid-

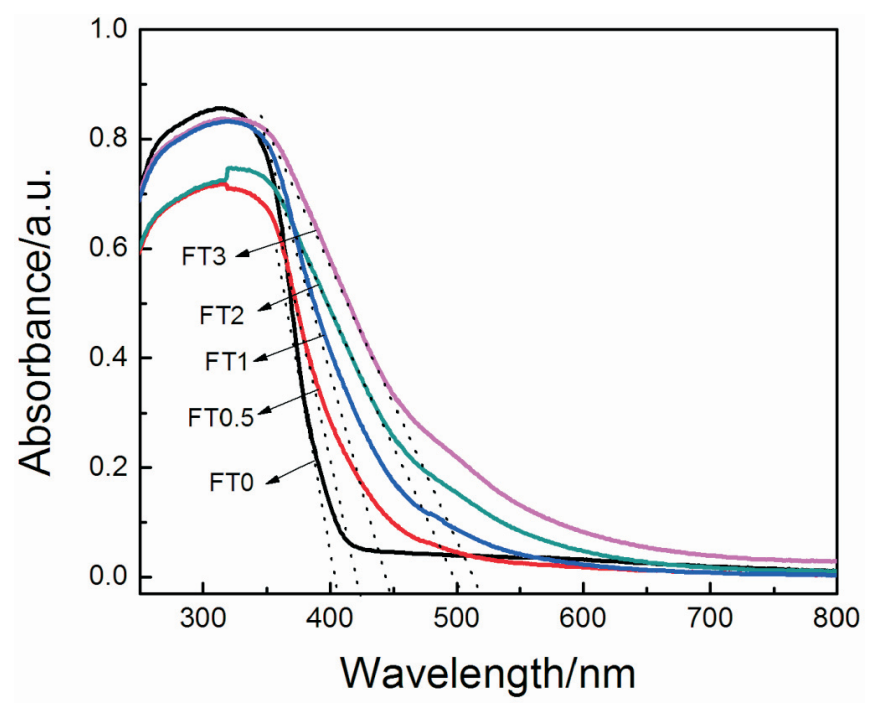

Figure 5 The UV-vis DRS spectrum of prepared samples. 
Table 2 The light absorption threshold and forbidden band width of $\mathrm{Fe}_{2} \mathrm{O}_{3} / \mathrm{TiO}_{2}$ photocatalysts.

\begin{tabular}{lccccc}
\hline & \multicolumn{5}{c}{ Photocatalysts } \\
\cline { 2 - 6 } & FT0 & FT0.5 & FT1 & FT2 & FT3 \\
\hline$\lambda \mathrm{g} / \mathrm{nm}$ & 409.76 & 425.15 & 446.77 & 499.53 & 519.67 \\
$\mathrm{Eg} / \mathrm{eV}$ & 3.02 & 2.92 & 2.78 & 2.48 & 2.38 \\
\hline
\end{tabular}

den band gap decreased to $2.38 \mathrm{eV}$. This is because the electronic structure of $\mathrm{TiO}_{2}$ were interfered after doping of $\mathrm{Fe}^{3+}$. Meanwhile, the d-d orbital transition $\left({ }^{2} \mathrm{~T}_{2 \mathrm{~g}} \rightarrow{ }^{2} \mathrm{~A}_{2 \mathrm{~g}}{ }^{2} \mathrm{~T}_{1 \mathrm{~g}}\right)$ of $\mathrm{Fe}^{3+}$ or the charge transition $\left(\mathrm{Fe}^{3+}+\mathrm{Fe}^{3+} \rightarrow \mathrm{Fe}^{2+}+\mathrm{Fe}^{4+}\right)$ between $\mathrm{Fe}^{3+}$ and $\mathrm{Fe}^{3+}$ can also cause the absorption band red shift. ${ }^{6}$

\subsection{Photocatalytic Activity}

The photocatalytic activities of monolithic $\mathrm{TiO}_{2}, \mathrm{Fe}_{2} \mathrm{O}_{3} / \mathrm{TiO}_{2}$ were evaluated by degradation of BPA in water with illumination. Control experiment indicates that BPA can be slightly degraded under $500 \mathrm{~W}$ xenon lamp irradiation without catalysts, which indicated that the photocatalytic process played the major role in the BPA degradation. Fig. 6 shows the degradation profiles of BPA wastewater under illumination with various photocatalysts. As one can see, the degradation of BPA by the FT3 is the most significant among all the prepared samples, about $85 \%$ of BPA was degraded after $6 \mathrm{~h}$. The improved activity can be ascribed to the narrow band gap and lower electronichole recombination rate of FT3. At the same time, doping of appropriate amounts of $\mathrm{Fe}$ can form more $\mathrm{Fe}(\mathrm{OH})^{2+}$. It is favourable for the photocatalytic reaction to have phenol hydroxyl groups and weak acidity. Therefore, a moderate amount of doping of Fe can improve the degradation rate of BPA effectively.

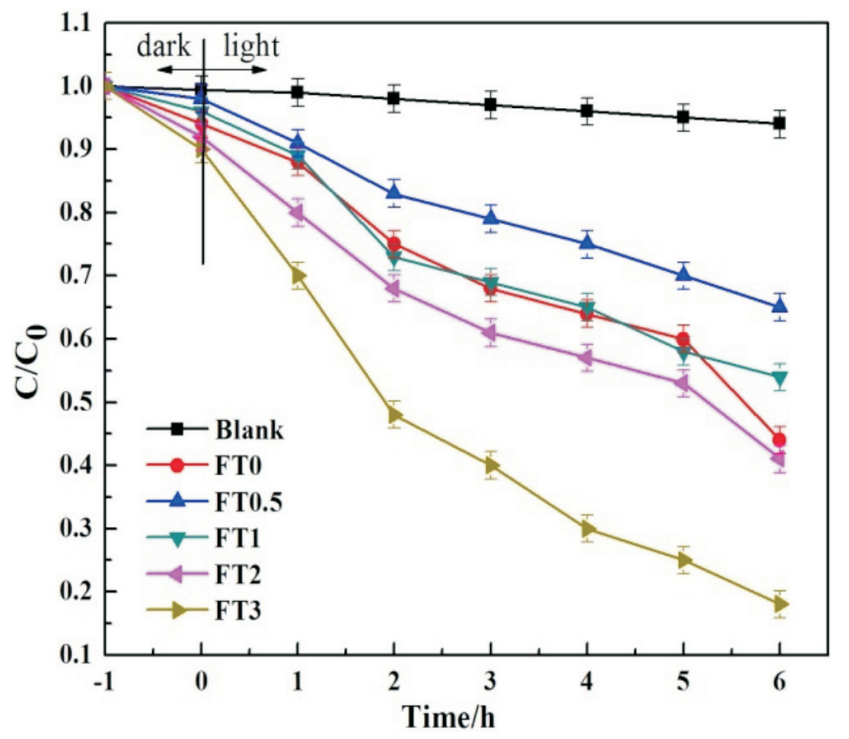

Figure 6 Degradation profiles of BPA over different samples (30 mg photocatalyst, $2 \times 10^{-5} \mathrm{~mol} \mathrm{~L}^{-1} \mathrm{BPA}$ in $50 \mathrm{~mL}$ aqueous solutions; the values with standard deviation less than 0.0215 for three times test).

\section{Conclusions}

The monolithic $\mathrm{Fe}_{2} \mathrm{O}_{3} / \mathrm{TiO}_{2}$ photocatalysts were successfully synthesized via a one-pot sol-gel process. With the doping of $\mathrm{Fe}$, the surface area of the monolithic $\mathrm{Fe}_{2} \mathrm{O}_{3} / \mathrm{TiO}_{2}$ increased, the absorption edge appeared red shifted and the electronic-hole recombination rate decreased and its quantum efficiency increased. Appropriate iron doping can improve the degrada- tion rate of BPA effectively. In addition, the monolithic $\mathrm{Fe}_{2} \mathrm{O}_{3} / \mathrm{TiO}_{2}$ photocatalysts are easier to recover in a practical application.

\section{Acknowledgements}

This work was supported by the Funds of Xi'an Polytechnic University Subject Construction (107090817), and the Cooperative Innovational Center for Technical Textiles, Shaanxi Province (2015ZX-25).

\section{References}

1 M. Auriol, Y.F. Meknassi and R.D. Tyagi, Endocrine disrupting compounds removal from wastewater, a new challenge, Process Biochem. 2006, 41, 525-539.

2 C. Kuo, C. Wu and H. Lin, Photocatalytic degradation of bisphenol A in a visible light/ $\mathrm{TiO}_{2}$ system, Desalination, 2010, 256, 37-42.

3 N.S. Begum and H.M.F. Ahmed, Synthesis of nanocrystalline $\mathrm{TiO}_{2}$ thin films by liquid phase deposition technique and its application for photocatalytic degradation studies, Bull. Mater. Sci., 2008, 31, 43-48.

4 B. Kılıç, N. Gedik, S.P. Mucur, A.S. Hergul and E. Gür, Band gap engineering and modifying surface of $\mathrm{TiO}_{2}$, nanostructures by $\mathrm{Fe}_{2} \mathrm{O}_{3}$, for enhanced-performance of dye sensitized solar cell. Mater. Sci. Semicond. Process., 2015, 31, 363-371.

5 H. Sun, G. Zhou, S. Liu, H. Ang, M. Tadé and S. Wang, Visible light responsive titania photocatalysts codoped by nitrogen and metal ( $\mathrm{Fe}$, $\mathrm{Ni}, \mathrm{Ag}$, or Pt) for remediation of aqueous pollutants, Chem. Eng. J., 2013, 231, 18-25.

6 S. Wang, J.S. Lian and W.T. Zheng, Photocatalytic property of Fe doped anatase and rutile $\mathrm{TiO}_{2}$ nanocrystal particles prepared by sol-gel technique, Appl. Surf. Sci., 2012, 263, 260-265.

7 W. Lv, S.Y. Chen and D.L. Chen, Preparation of $\mathrm{Zn}$ doped $\mathrm{TiO}_{2}$ composite nanofibers by electrospinning, J. Mater. Sci., 2010, 124, 217-221.

8 S. Ding, G.W. Zhu and R.W. Wang, Synthesis of carbon-doped mesoporous $\mathrm{TiO}_{2}$ visible-light photocatalytic materials via one pot solvo thermal method, Chem. J. Chinese Univ., 2014, 35, 1016-1022.

9 M. Nasirian, C.F. Bustillolecompte and M. Mehrvar, Photocatalytic efficiency of $\mathrm{Fe}_{2} \mathrm{O}_{3} / \mathrm{TiO}_{2}$ for the degradation of typical dyes in textile industries: effects of calcination temperature and UV-assisted thermal synthesis, J. Environ. Manage., 2017, 196, 487-498.

10 P. Xu, Y.S. Li and C. Liu, Preparation and visible-light driven photocatalytic performance of mesoporous titania doped with silver, J. Chinese Ceramic Soc., 2014, 14, 1195-1202.

11 M.V. Dozzi, S. Brocato, G. Marra, G. Tozzola, L. Meda and E. Selli, Aqueous ammonia abatement on Pt-and $\mathrm{Ru}$-modified $\mathrm{TiO}_{2}$ : selectivity effects of the metal nanoparticles deposition method, Catal. Today, 2017, 287, 148-154.

12 C. Noberi, F. Kaya and C. Kaya, Synthesis, structure and characterization of hydrothermally synthesised $\mathrm{Ag}-\mathrm{TiO}_{2}$, nano-structures onto Ni filters using electrophoretic deposition, Ceram. Int., 2016, 42(15), 17202-17209.

13 K. Tahir, A. Ahmad, B. Li, A.U. Khan, S. Nazir, S. Khan, Z.U.H. Khan and S.U. Khan, Preparation, characterization and an efficient photocatalytic activity of $\mathrm{Au} / \mathrm{TiO}_{2}$, nanocomposite prepared by green deposition method, Mater. Lett., 2016, 178, 56-59.

14 M. Gharagozlou and R. Bayati, Photocatalytic characteristics of single phase Fe-doped anatase $\mathrm{TiO}_{2}$ nanoparticles sensitized with vitamin B12, Mater. Res. Bull., 2014, 61, 340-347.

15 S.S. Lee, H. Bai, Z. Liu and D. Sun, Optimization and an insightful properties - Activity study of electrospun $\mathrm{TiO}_{2} / \mathrm{CuO}$ composite nanofibers for efficient photocatalytic $\mathrm{H}_{2}$ generation, Appl. Catal. B: Environ., 2013, 140-141, 68-81.

16 A. Luengnaruemitchai, K. Srihamat, C. Pojanavaraphan and R. Wanchanthuek, Activity of $\mathrm{Au} / \mathrm{Fe}_{2} \mathrm{O}_{3}-\mathrm{TiO}_{2}$, catalyst for preferential CO oxidation, Int. J. Hydrogen Energy, 2015, 40(39), 13443-13455.

17 J.Y. Li, Z.X. Song, P. Ning, Q.L. Zhang, X. Liu, H. Li and Z.Z. Huang, Influence of calcination temperature on selective catalytic reduction of $\mathrm{NOx}$ with $\mathrm{NH}_{3}$ over $\mathrm{CeO}_{2}-\mathrm{WO}_{3} / \mathrm{TiO}_{2}$ catalyst, J. Rare Earths, 2015, 33(7), 726-735.

18 M. Naimi-Joubani, M. Shirzad-Siboni, J.K. Yang, M. Gholami and M. Farzadkia, Photocatalytic reduction of hexavalent chromium with illuminated $\mathrm{ZnO} / \mathrm{TiO}_{2}$ composite, J. Ind. Eng. Chem., 2015, 22, 317-323. 
19 K.R. Wee, B.D. Sherman, M.K. Brennaman, M.V. Sheridan, A. Nayak, L. Alibabaei and T.J. Meyer, An aqueous, organic dye derivatized $\mathrm{SnO}_{2} / \mathrm{TiO}_{2}$ core/shell photoanode, J. Mater. Chem. A, 2016, 4(8), 2969-2975.

20 W. Deng, Q.G. Dai,Y.J. Lao, B.B. Shi and X.Y. Wang, Low temperature catalytic combustion of 1, 2-dichlorobenzene over $\mathrm{CeO}_{2}-\mathrm{TiO}_{2}$ mixed oxide catalysts, Appl. Catal. B: Environ., 2016, 181, 848-861.

21 J.Q. Li, D.F. Wang, Z.Y. Guo and Z.F. Zhu, Preparation, characterization and visible-light-driven photocatalytic activity of Fe-incorporated $\mathrm{TiO}_{2}$ microspheres photocatalysts, Appl. Surf. Sci., 2012, 263, 382-388.

22 S. Leong, A. Razmjou, K. Wang, K. Hapgood and X. Zhang, $\mathrm{TiO}_{2}$ based photocatalytic membranes: a review, J. Membr. Sci., 2014, 472, 167-184.

23 G.L. Drisko, A. Zelcer and X.D.Wang, Synthesis and photocatalytic activity of titania monoliths prepared with controlled macro- and mesopore structure, Appl. Mater. Inter., 2012, 4, 4123-4130.

24 J.F. Lei,X.P. Li, W.S. Li, Photocatalytic degradation of methyl orange on arrayed porous iron-doped anatase $\mathrm{TiO}_{2}$. J. Solid State Electrochem., $2012, \mathbf{1 6}, 625-632$

25 Q.Q. Wang, S.H. Xu and F.L.Shen, Preparation and characterization of $\mathrm{TiO}_{2}$ photo-catalysts co-doped with iron (III) and lanthanum for the degradation of organic pollutants. Appl. Surf. Sci., 2011, 257, 7671-7677.

26 N. Wu, Q.F. Wei and L. Chen, Preparation, characterization and photocatalytic properties of $\mathrm{Fe}^{3+}$ doped $\mathrm{TiO}_{2}$ nanofibers, J. Textile Res. $2011,32,5-9$.

27 G.H. Xu and J.G. Yu, Visible-light-induced photo-electrochemical behaviors of Fe modified $\mathrm{TiO}_{2}$ nanotube arrays, Nanoscale, 2011, 3, 3138-3144.

28 S.D. Deldkar, H.M. Yadav, S.N. Achary, S.S. Meena and S.H. Pawar, Structural refinement and photocatalytic activity of Fe-doped anatase $\mathrm{TiO}_{2}$ nanoparticles, Appl. Surf. Sci., 2012, 263, 536-545.

29 G.R. Yang, Q. Zhang, W. Chang and W. Yan, Fabrication of $\mathrm{Cd}_{1-\mathrm{x}} \mathrm{Zn}_{\mathrm{x}} \mathrm{S} /$ $\mathrm{TiO}_{2}$ heterostructures with enhanced photocatalytic activity, J. Alloy. Compd., 2013, 580, 29-36. 